\title{
WHATEVER FLOATS YOUR BOAT
}

Shipping is one of the most fuel-efficient ways to move freight, but the industry still produces significant greenhouse-gas emissions, including more than a quarter of the world's nitrogen oxides emissions. And it also produces more sulphur dioxide emissions than all land transportation combined. In the latest of our Future Transport series, Duncan Graham-Rowe looks at the new wave in shipping.
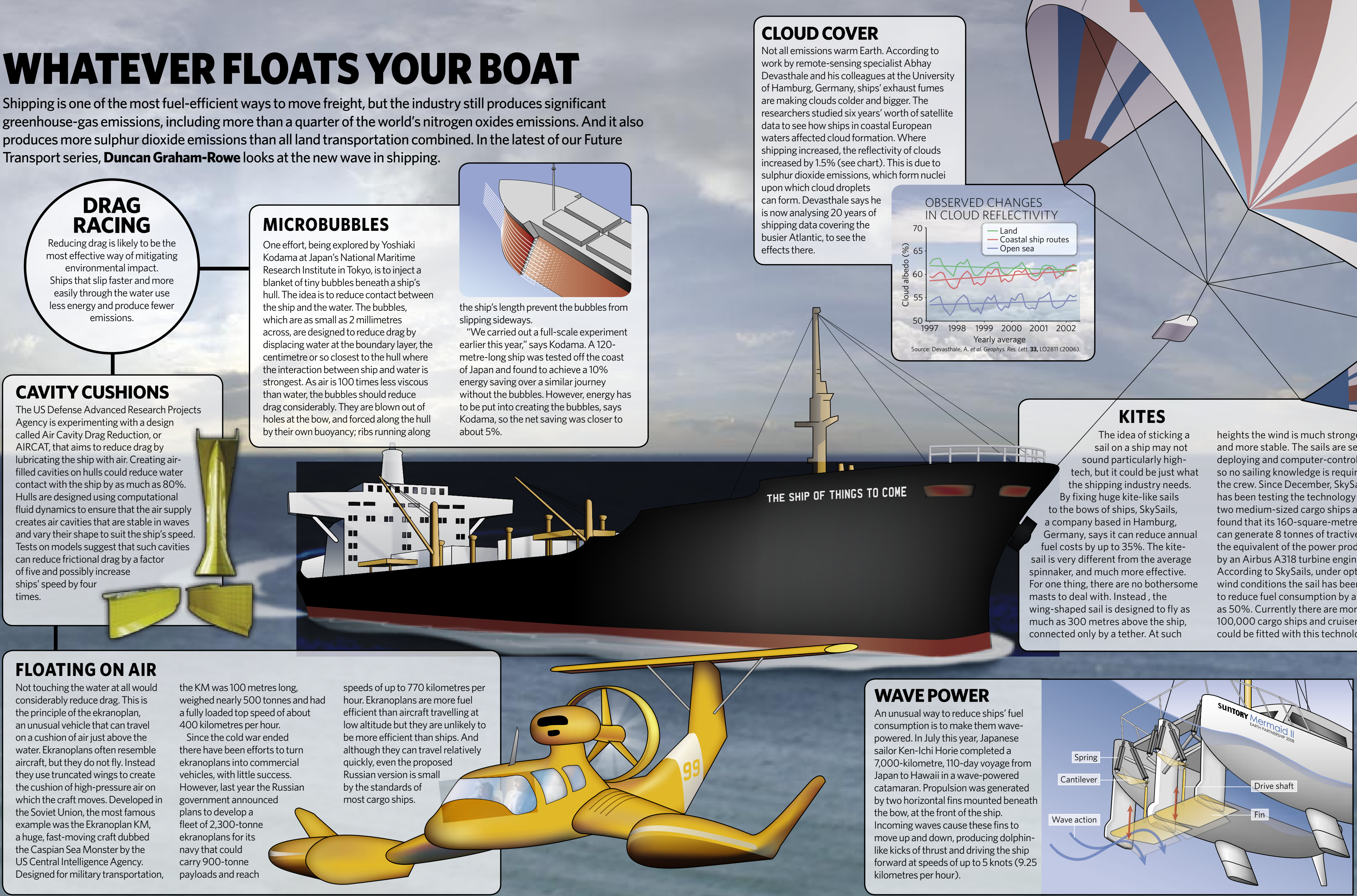

\section{FLOATING ON AIR}

Not touching the water at all would
considerably reduce drag. This is

the principle of the ekranoplan

on a cushion of air just above the

aircraft, but they do not fly. Instead

they use truncated wings to create
the cushion of high-pressure air on

which the craft moves. Developed

example was the Ekranoplan KM,

the Caspian Sea Monster by the

US Central Intelligence Agency.

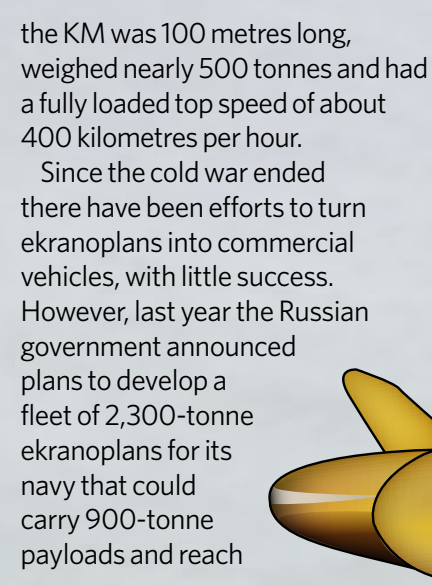

speeds of up to 770 kilometres per

hour. Ekranoplans are more fuel
efficient than aircraft travelling

low altitude but they are unlikely

be more efficient than ships. An

quickly, even the proposed

Russian version is smal
by the standards of

by the standards of
most cargo ships. 